\title{
Alternative Mechanisms to Reduce Food Price Volatility and Price Spikes: Policy Responses at the Global Level
}

\author{
Maximo Torero
}

\subsection{Background}

The food price crisis of 2007-2008 saw a steep rise in food prices, which brought food security to the forefront of global attention. In June 2010, food prices started rising again; between June 2010 and May 2011, the international prices of maize and wheat roughly doubled. Food prices peaked in February 2011. According to the Food and Agriculture Organization of the United Nations (FAO), the spike in 2011 was even more pronounced than in 2008 (see, for example, the evolution of maize prices in Fig. 6.1, which exceeded the levels of prices in 2008 even when adjusted for inflation). Moreover, recent increases in price volatility are not in line with historical data (dating back to the late 1950s) and have particularly affected wheat and maize in recent years. For soft wheat (used for cakes and pastries), for example, there were 207 days of excessive price volatility between December 2001 and December 2006 (an average of 41 days a year), whereas there were 395 days of excessive price volatility between January 2007 and June 2011 (an average of 88 days a year), as shown in Fig. 6.2.

The 2007-2008 food price crisis led to economic difficulties, particularly for the already poor population. Despite the varying level of price transmission from international to local markets among regions, it generated social and political

\footnotetext{
M. Torero $(\bowtie)$

International Food Policy Research Institute (IFPRI), 2033 K St. NW, Washington, DC 20006, USA

e-mail: m.torero@cgiar.org
} 


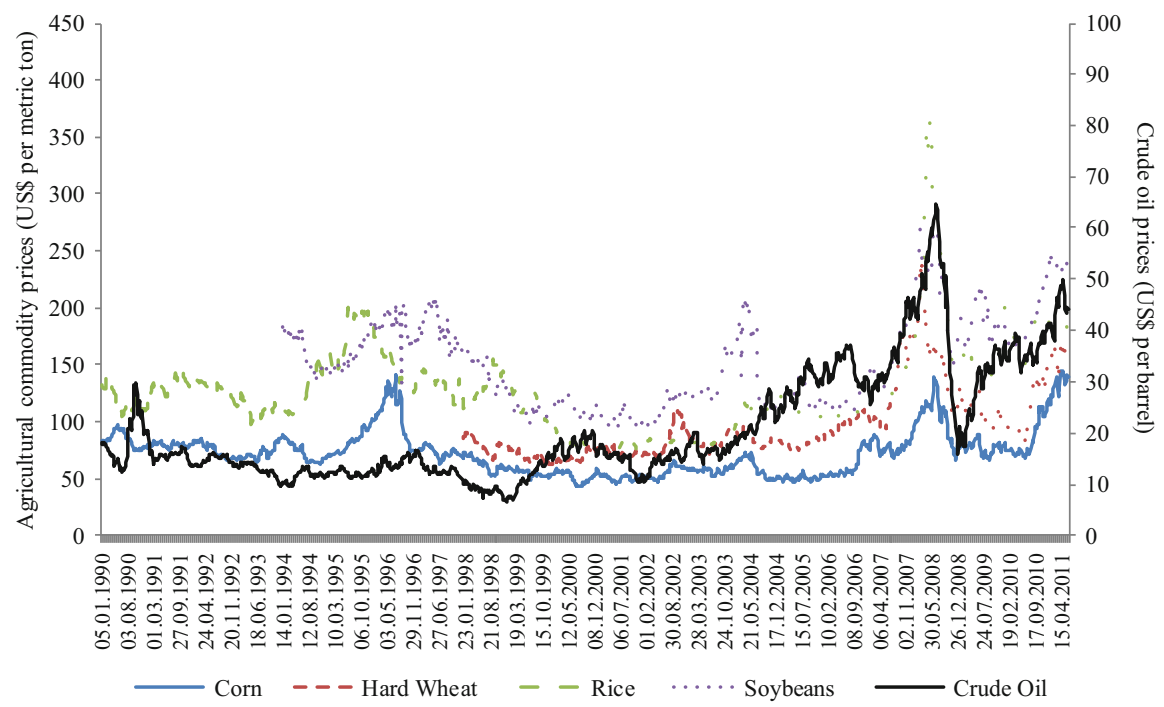

Fig. 6.1 Inflation-adjusted prices of agricultural commodities and oil, 1990-2011 (weekly data). Note: corn is U.S. no. 2 yellow, wheat is U.S. no. 2 hard red winter, rice is white Thai A1 super, soybeans is U.S. no. 1 yellow, and crude oil is spot price from Cushing, Oklahoma WTI. Source: FAOSTAT Online, Grain Council, and U.S. Energy Information Administration

turmoil in many countries. In addition, food price spikes and excessive volatility worsened the problem of hunger by increasing poverty (see Chap. 1 of this book for a detailed review of the nutritional impacts). The effects of high and volatile food prices are also particularly harmful for countries with high net food imports, and high food inflation affects countries with large numbers of poor people, such as China, India, and Indonesia.

As long-term solutions to the food price crisis are sought, it is important to understand the root causes of the problem. The crisis was triggered by a complex set of long- and short-term factors, including policy failures and market overreactions. In this respect, Table 6.1 shows a more complete discussion of the different demandand supply-side factors that contributed to the 2007-2008 food price crisis.

As shown in Table 6.1, outside of traditional fundamentals, an important factor contributing to the crisis may have been the entry of significant financial resources into futures markets, including food commodity markets. This large financial inflow of resources may have contributed to a price spike during the first 6 months of 2008 and also later in 2010. It is important to note that there is no consensus among experts on this; there is, however, significant discussion surrounding the possibility that channeling financial resources through commodity futures markets, by speculators in particular, may have triggered the food crisis. Establishing theoretical and empirical linkages between future prices and spot prices is not easy, and testing causality is even more complex (for the theory on the topic, see Sanders and Irwin 2010 and see Chap. 1 for a detailed discussion). 


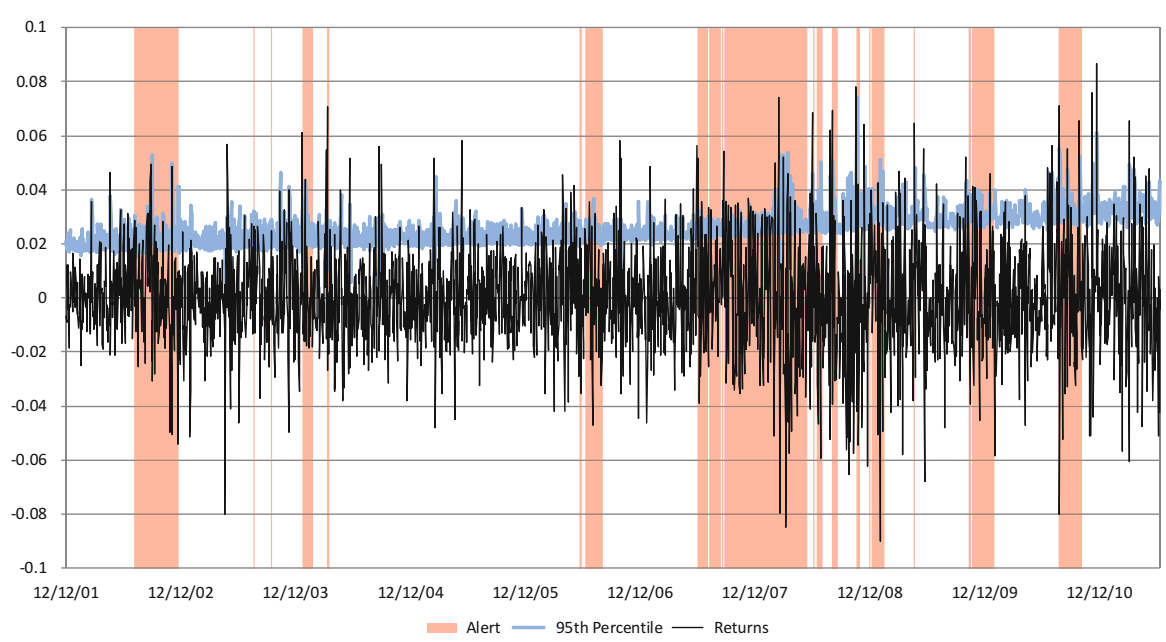

Fig. 6.2 Excessive food price volatility for hard wheat. Note: This figure shows the results of a model of the dynamic evolution of daily returns based on historical data going back to 1954 (known as the Nonparametric Extreme Quantile (NEXQ) Model). This model is then combined with extreme value theory to estimate higher-order quantiles of the return series, allowing for classification of any particular realized return (that is, effective return in the futures market) as extremely high or not. The blue line is a logarithm of the observed daily return (rate of increase of prices from 1 day to the other) on investment. The red line represents a level below which returns have a $95 \%$ probability of occurring (i.e., the higher-order return estimated by the NEXQ model). When the blue line (return) exceeds the red line (95th percentile), it is characterized as an excessively large return. One or two such returns do not necessarily indicate a period of excessive volatility. Periods of excessive volatility are identified based on a statistical test applied to the number of times the extreme value occurs in a window of consecutive 60 days. Source: MartinsFilho et al. (2010). See details at http://www.foodsecurityportal.org/soft-wheat-price-volatilityalert-mechanism

Today's agricultural markets have three key characteristics that increase price responses to any of the drivers behind the causes of rising prices and volatility. First, export markets for all staple commodities-rice, maize, wheat, and soybeans-are highly concentrated in a few countries or very thin (that is, only a small share of production is traded). In the case of both maize and rice, the top five producers account for more than $70 \%$ of global production, and the top five exporters account for about $80 \%$ of world exports. For wheat, the top five producers and exporters account for about 50 and $60 \%$ of global production and exports, respectively. These high levels of concentration imply that the world's capacity in coping with geographical risk is limited. Any weather shocks or exogenous shocks to production in these countries will immediately have an effect on global prices and price volatility. Second, the world's maize reserves and restricted wheat reserves are now at historically low levels. To function effectively, the market requires a minimum level of grain reserves to serve as a buffer against sudden changes in supply or demand. These reserves are needed because the supply of and demand for grain 


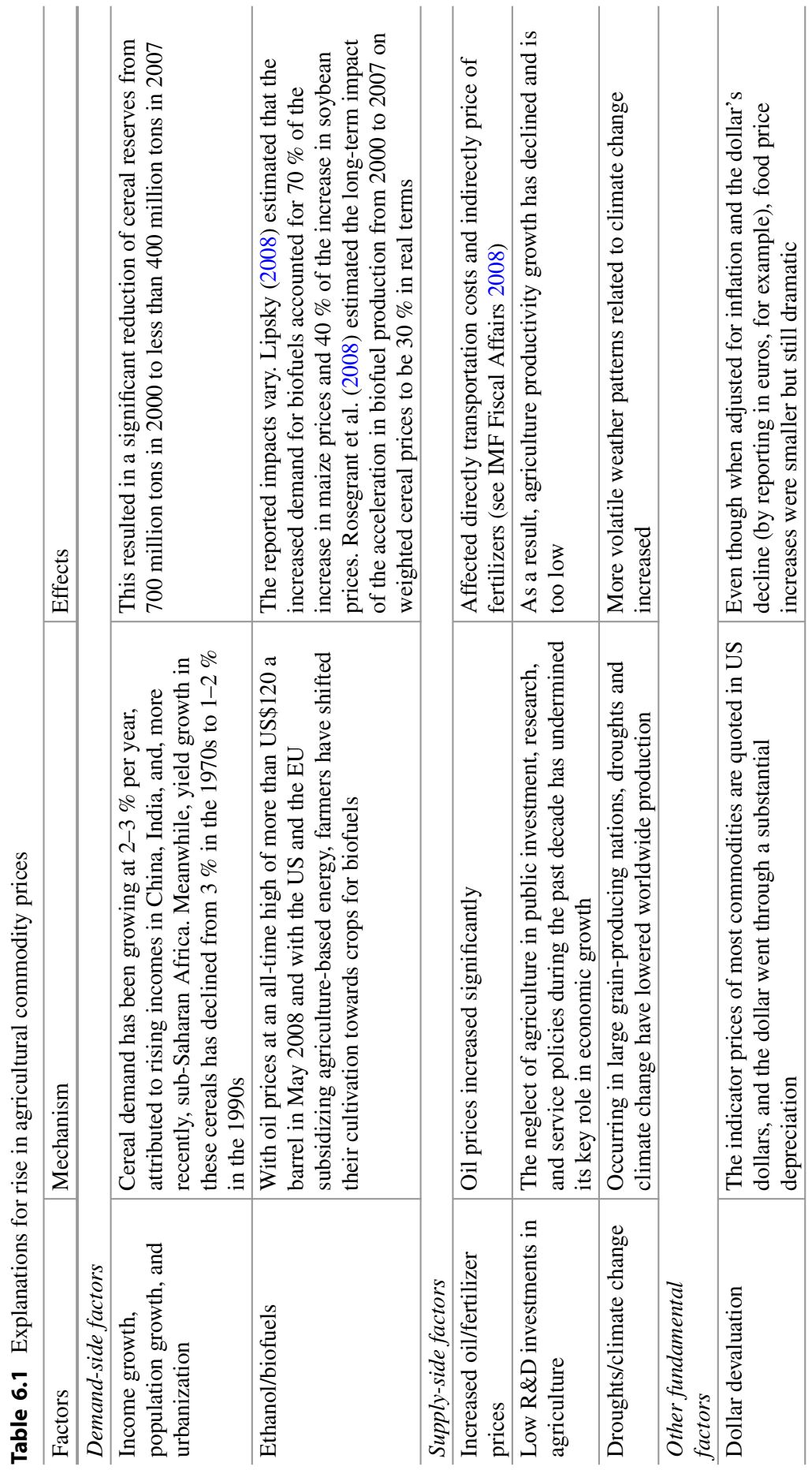




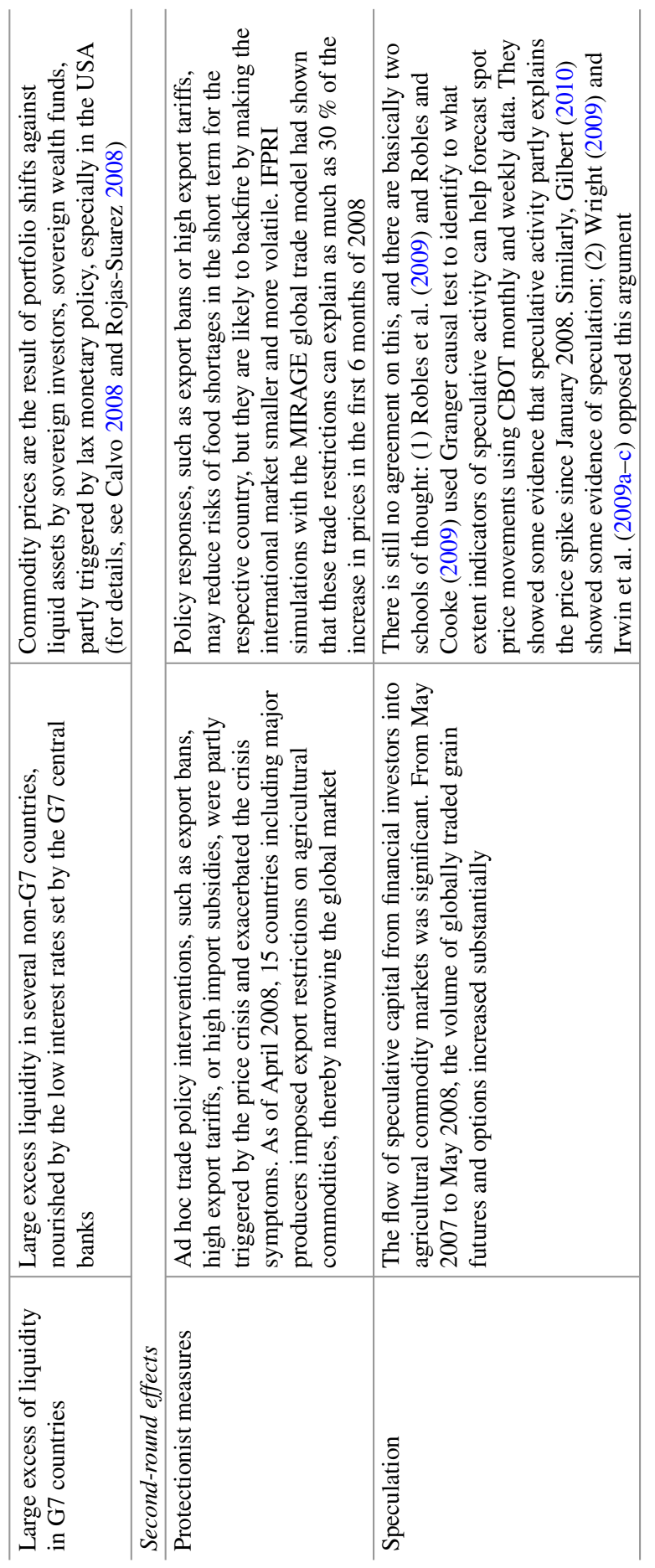


are not very responsive to price changes in the short term. When prices go up, for example, it is difficult for farmers to immediately produce more or for consumers to immediately consume less. As a result, any supply shocks, caused by events such as a drought or flood, can lead to price spikes and hoarding by farmers seeking to take advantage of higher prices in the future. In both 1973 and 2007, global grain stocks hit record lows, prompting the global food crises. Insufficient stocks can lead to large price increases and a breakdown of functioning markets. In 2007-2008, grain stocks were only about 60 million tons ( $2.7 \%$ of global production) lower than in 2004-2005. But as evident in prices rising sharply in 2007-2008, this difference in grain stocks was enough to cause serious problems in the market, especially for commodities whose production is concentrated in just a few countries, such as rice (Timmer 2010). Third, appropriate, timely information on food production, stock levels, and price forecasting is sorely lacking. When this information gap leads to overreactions by policymakers and traders, it could result in soaring prices.

In summary, despite the recent literature regarding the potential causes of the 2007-2008 and 2010 crises, we do not yet have a definitive causal diagnosis that analyzes all the potential causes on a quantitative basis. As a result, it is even more difficult to analyze the potential policies that are necessary to avoid such a crisis in the near and long-term future. However, the general consensus is that this episode and what has been happening since October 2010 highlight the need for more research into the architecture of international financial and agricultural markets so that we can identify proper mechanisms for reducing price spikes and extreme price volatility, especially given the extreme impacts they have on the livelihoods of the poor (Sommer and Gilbert 2006; Bakary 2008; Brahmbhatt and Christiaensen 2008; OECD 2008; UNCTAD 2009; von Braun 2008a-c; von Braun et al. 2008; World Agricultural Outlook Board 2008; Headey and Fan 2010; HM Government 2010).

The new global reality involves both higher and more volatile prices-two different conditions with distinct implications for consumers and producers. For several decades, the dominant approach to managing food price volatility has been to stabilize income without affecting prices. The idea behind this approach is that prices guide behavior, so any attempt to change prices damages this mechanism of resource allocation. At the same time, the "natural" insurance that comes from the negative correlation between harvest size and price level stabilizes producers' incomes - in particular in closed economies. Thus, any effort to stabilize food prices reduces the correlation between prices and harvests and disrupts the existing natural equilibrium. Under this strategy, private insurance and hedging instruments, along with public instruments targeting vulnerable households, are used to manage risk and stabilize prices. However, in the changing global economy, local prices are becoming less correlated to local harvests, and prices do not always convey the appropriate information to economic agents. Mechanisms to reduce excessive price volatility then become essential in eliminating the endogenous component of price instability without affecting the natural price instability component. ${ }^{1}$

${ }^{1}$ For more information, see Galtier (2009). 
In the short term, both the supply of and demand for grain are very inelastic. Droughts, floods, or any other severe weather shocks can have significant impact on country-level supply because grain production is so sensitive to weather events. Combined with demand inelasticity, any supply shocks can lead to price spikes and hoarding behavior by farmers trying to take advantage of higher prices in the future. At a regional level, on the other hand, grain production is less affected by weather, and shortages in production in certain areas can be compensated for by higher production in other areas. As a result, international trade can reduce the need for large national-level grain reserves. However, because so many countries had reduced their public grain reserves by 2007, when prices began to rise, many governments had no mechanism for stabilizing their grain markets. A few countries did have sufficient reserves but did not want to sacrifice those reserves to stabilize the global market. Governments in a few exporting countries further worsened the situation by temporarily establishing export barriers and reducing import barriers; thus, by adding upward pressure on commodity markets, global market stability was sacrificed in order to stabilize domestic prices.

Variable temperatures, changes in precipitation patterns, and increased occurrence of extreme weather events brought about by climate change, such as droughts and floods, will increasingly affect the global food supply. As a result, the global community will have to increasingly deal with the issues prompted by the food price and financial crises of recent years as prices are increasingly affected by both supply and demand issues around the world. From these crises, it is evident that governments will find it difficult to deal with these issues at a national level.

A careful analysis of the different policies that could be implemented to reduce or diminish the effects of increasing price volatility, and especially to reduce the probability of significant price spikes, is therefore necessary. The price spike episode of early 2008 clearly highlighted the need to modify the institutional architecture of international financial and agricultural markets to address their effects on the livelihoods of the poor. This chapter reviews the most prominent policy proposals aimed at reforming international agricultural markets and addressing price volatility at the international scale.

\subsection{Review of Policies Proposed/Implemented to Reduce Price Volatility Before 2007}

Physical reserves have been used at national, regional, and international level at different times throughout history to control price spikes and reduce price variability. For decades, large countries, such as China and India have kept a significant level of physical reserves because of their size and the effects that their entry into world markets would have on prices during harvest shortfalls. The US operated a farmer-owned reserve for several decades. The farmers received loans and money as reimbursement for their storage costs; in exchange, they were required to follow stipulations concerning when the stored grain could be sold. The farm bill passed in 1996; however, it virtually eliminated physical grain reserves. 
Many African countries, including Burkina Faso, Mali, Mozambique, Niger, Ethiopia, and Tanzania, established national-based food security reserve stocks between 1975 and 1980. During the time, agriculture was heavily managed, and because global grain prices were extremely high, many of these governments did not trust world markets to be secure sources of grain during an emergency. However, it proved to be quite difficult to accurately estimate how much grain was actually needed in these reserves. There was a tendency to overestimate the amount of grain needed in an emergency (Rashid and Lemma 2010). Quantities were based on estimates of normal consumption; in reality, however, people facing hunger eat less and often switch to cheaper foods, which then make up some of the shortfall. There were a number of other difficulties which eventually led to the disappearance of these food security reserve stocks in most countries, including the use of the reserves in normal market operations by the parastatals, insufficient resources to replenish reserves, and the unwillingness of donors to support these activities. Interest in the establishment of strategic grain reserves was revived following the liberalization of the cereal markets during the structural adjustment of the 1990s. Governments attempted to insure against the failure of the private sector during this period, but many of the experiences in managing these reserves were similar to previous attempts at operating grain reserves. Mismanagement, corruption, damaged donor relations, and erroneous estimates of consumption and production plagued governments as they tried to manage these reserves.

Interest in regional reserves also increased after the last food price spike in 1973 1974. The FAO (1980) noted the establishment of the Association of Southeast Asian Nations (ASEAN)'s Food Security Reserve (which was never operational) and also a proposal by CILSS (Inter-State Committee on Drought in the Sahel) to establish a regional reserve in the Sahel. The FAO provided technical assistance to support these initiatives. The idea of creating a regional food reserve for Mediterranean countries was also put forward, but it was not until the recent food crises that the ASEAN initiative was reactivated. To ensure food security in the region, ASEAN has established various cooperation programs, one of which is the East Asia Emergency Rice Reserve (EAERR). The EAERR is a regional cooperation program between the ten ASEAN member states, China, Japan, and the Republic of Korea. Specifically, it is an initiative of the ASEAN Ministers on Agriculture and Forestry and the Ministers of Agriculture of the People's Republic of China, Japan, and the Republic of Korea (AMAF Plus Three) to provide food assistance, strengthen food security in emergencies caused by disasters, and alleviate poverty. The EAERR is therefore a mutual assistance system through which rice stocks are shared between the 13 countries. It also aims to contribute to price stability of rice in the region (Chap. 17 by Irfan Mujahid and Lukas Kornher estimate the benefits of the EAERR through risk pooling). The EAERR plans to develop a proposal to upgrade the pilot project to a full-fledged scheme among the ASEAN Plus Three countries. The ASEAN Plus Three Agreement on Emergency Rice Reserve is currently being drafted for this purpose. However, the realization of a permanent scheme is subject to internal consultation, further assessment, and the evaluation of the outcomes of the pilot project. For a mechanism like the EAERR 
to work, political support from the ASEAN Plus Three countries is necessary. The EAERR pilot project is closely related to the ASEAN Food Security Information System (AFSIS) project and the work of the ASEAN Food Security Reserve Board $(\mathrm{AFSRB})^{2}$ in establishing food security in the region.

International commodity agreements (ICAs) (see Gilbert 1987, 1996) were established to stabilize individual commodity prices at the global level after the Second World War. However, most of these agreements collapsed, and by the early 1960s, only the agreements for wheat, sugar, coffee, tin, and olive oil remained. Although opinions differ as to why these agreements were not successful, the ICAs mostly played a peripheral role in stabilizing prices. The ICA on rubber actually had procedures to deal with increases and decreases in its price bands, but because it followed market prices for the most part, it was only able to smooth, not stabilize, prices. The cocoa and sugar agreements were simply too weak to accomplish their objectives, while the tin agreement was trying to hold prices at levels which were too high without the necessary financial backing. The agreement on coffee was arguably the most successful in raising and stabilizing prices before it lost consumer support and collapsed. Although some of the governing bodies of the ICAs still exist, ${ }^{3}$ these days they mostly assist the respective industries by publishing relevant statistics and studies rather than stabilizing prices.

Price stability and a stable supply of wheat were maintained during the early years of the International Grains Council (previously the International Wheat Council). However, this is most likely due to the relative stability of the supply and demand during this time; the agreements broke down during the 1973-1974 food crisis. Prompted by the price shock, international interest in grain reserves was reignited, and the United Nations Conference on Trade and Development (UNCTAD) organized discussions on the possibility of establishing international grain reserves (Wright and Bobenrieth 2009). The idea was to hold stocks nationally while managing them internationally, but issues of trigger price levels, stock levels and contributions, and special provisions for developing countries caused the discussions to fail, and the proposed international grain reserve was not established.

\subsection{Review of Policies Proposed as a Result of the 2007-2008 and 2010 Food Price Crises}

Following the food price crisis of 2007-2008 and the events since October 2010, there have been numerous proposals aimed at preventing such events from occurring again. The proposed plans address a range of ideas for improvement, including

\footnotetext{
${ }^{2}$ The AFSRB is an ASEAN mechanism for sharing of rice stocks in times of shortage, particularly through the trigger of a collective operation of the committed ASEAN Emergency Rice Reserve (AERR). Currently, the total quantity of the AERR is 87,000 metric tonnes for emergency purposes.

${ }^{3}$ Coffee (ICO); cocoa (ICCO); cereals, oilseeds (IGC); sugar (ISO); jute (IJSG); rubber (IRSG); bamboo, rattan (INBAR); tropical timber (ITTO); cotton (ICAC); olives, olive oil (IOOC).
} 
physical reserves at different levels, virtual reserves, improvements in information and coordination, and trade facilitation. Several proposals have been made for storage: emergency reserves for food aid, internationally coordinated public grain reserves, and national and regional stocks. More than ten proposals have been put forward with the aim of preventing price spikes and price volatility in the future. These proposals can be grouped as follows: (a) information and research, (b) trade facilitation, (c) reserves and stocks, (d) financial instruments, and (e) regulatory proposals.

\subsubsection{Information}

There are two key proposals for improving information and coordination in order to increase market confidence and relieve temporary disruptions in supply. First, Wright (2008, 2009) and Evans (2009) proposed an international food agency (IFA); second, Martins-Filho et al. (2010) proposed an early warning mechanism (EWM) to identify price abnormalities.

Wright (2009) argued that confidence in markets could be increased if there were more and better information regarding stocks. Similarly, Evans (2009) and Wright (2008) proposed the creation of an IFA, modeled after the International Energy Agency (IEA) ${ }^{4}$ which would report on stock levels and develop protocols for international collaboration to improve the global response to shortages and help prevent the onset of market panic. Two potential criticisms are central to this proposal. First, many international agencies are not optimistic that better information regarding existing stocks and their evolution can be generated without considerable effort, international coordination, and costs. This is even more relevant given the current lack of appropriate information regarding public holding of stocks by key producer countries such as China and India; there are also much stocks held by private enterprises which consider their stock levels as commercial secrets. The lack of appropriate information on and knowledge of the holders and the type of stocks at a given time calls into question the development of the IFA as proposed by Evans (2009). Second, it is unclear how emergency response protocols could be agreed upon at such levels of asymmetry of information or which mechanisms would be used to identify critical levels of stocks which would necessitate the IFA to call for a collaborative international response. Resolving both of these problems could be extremely costly, although the availability of information on physical stocks at the global level could by itself help to reduce price volatility.

\footnotetext{
${ }^{4}$ The IEA was established in 1974 in the wake of that commodities spike. It reports on public and private petroleum stocks in OECD member states and has developed protocols for international collaboration in assuring supplies reach a member country should there be a disruption to their import market (Wiggins and Keats 2009a, b).
} 
Martins-Filho et al. (2010) $)^{5}$ proposed a model for estimating conditional quantiles for log returns of future prices (contracts expiring between 1 and 3 months) of hard wheat, soft wheat, corn, and soybeans. This fully nonparametric model identifies the cases in which the values of the realized returns (log returns of future prices contracts expiring between 1 and 3 months) are higher than the forecast $95 \%$ conditional quantile for the log return on the following day based on a model that includes daily returns since 2001 . When this event happens, it means that the realized return is an abnormality, and we expect it to fall under the 95th percentile return on the following day. This additional market information could in itself help to reduce potential asymmetry of information among buyers and sellers and therefore helping to reduce extreme price volatility. One main caveat of the model is that it is currently operating only for commodities traded in the futures market, but the framework can also be extended to spot markets if better price information existed.

The G20 has clearly understood the need for better information and has agreed to launch the Agricultural Market Information System (AMIS) to encourage major players in the global agrifood market to share data, enhance existing information systems, promote greater understanding of food price developments, and advance policy dialogue and cooperation. AMIS, in a way, captures both of the proposals explained before. If properly linked to existing global, regional, or national early warning systems for food security and vulnerability, AMIS could substantially improve countries' capacity to make appropriate decisions regarding food security matters and help reduce price volatility. However, as the UN Special Rapporteur on the Right to Food, Olivier De Schutter (2010), has already pointed out, without the full participation of the private sector, the information will be incomplete. So far, private companies are merely urged to participate in AMIS. Support should be provided to build national and regional capacity to develop and implement transparent and publicly accessible food security monitoring and information systems.

\subsubsection{Trade Facilitation}

Other proposals aim to facilitate trade in order to reduce risks in grain trading when supplies are low and to avoid disruptions in grain market. Sarris (2009) proposed a type of food import financing facility (FIFF) that would alleviate financing constraints as well as an International Grain Clearinghouse Arrangement (IGCA) to ensure the availability of staple food imports. This international clearing house would reduce the risk of exporters reneging on contracts when supplies are tight by guaranteeing contracts for grain deliveries. Finally, Wright (2009) and Lin (2008)

\footnotetext{
${ }^{5}$ For further details see http://www.foodsecurityportal.org/sites/default/files/MartinsFilhoToreroYao2010.pdf
} 
took a different approach to trade facilitation (TF) with plans to prevent export bans in order to avoid any disruption of supplies.

The FIFF was initially proposed to the IMF in the early 1980 s by the World Food Council and the FAO, and it was implemented in May 1981, although as mentioned it raised several questions about its possible effect on world grain prices. The facility could create a significant increase in demand for grains in developing countries in years of tight supply and thus could put strong upward pressure on prices. Moreover, despite its existence, the facility has not been used in the last 10 years, not even during the 2007-2008 crisis. According to Shaw (2007), "terms for accessing the facility were set too high to make it attractive or acceptable." When countries have existing balance of payment weaknesses, they cannot access the FIFF without a parallel fund-supported adjustment program. If this facility is to be used more as a humanitarian instrument as a result of the price crises, it clearly seems to be targeting more on emergency situations rather than directly on reducing price volatility. In addition, the facility is susceptible to significant governance problems and costs, and it would be necessary to develop an independent FIFF without IMF-attached conditionalities (for further details, see Huddleston et al. 1984; Valdés 1981; Adams 1983).

On the other hand, the IGCA proposal, as mentioned by Wiggins and Keats (2009a, b), looks somewhat similar to the International Commodity Clearing House (ICCH) proposed in 1949. Wiggins and Keats pointed out that at that the world food situation was characterized by commodity surpluses in areas with strong currencies (particularly the US dollar), while countries with weaker currencies and insufficient supplies could not afford imports. This led to the ICCH proposal: a public corporation to be housed in the FAO with a budget of US $\$ 5$ billion. The initial proposal covered half a dozen main functions, which included the coordination and negotiation of bilateral and multilateral trade agreements, but given its complexity and the requirement need to transfer power to multilateral organizations, it was rejected by FAO member nations.

In the current revision of the IGCA proposal, as explained by Wiggins and Keats $(2009 a, b)$, grain trade contracts (between countries or private entities) in the medium- and long-term would be guaranteed. It would be housed in an existing institution, such as an international bank or multilateral financial institution, and would function as a holding body for a "good faith margin" contributed by the buyer and the seller in any particular contract. These amounts, posted as margins, could be borrowed from international banks or other multilateral financial institutions. To guarantee availability of physical supplies, the IGCA would invest its financial reserves in physical stocks of grain in locations of excess supply or in the form of futures contracts in organized commodity exchanges. Any commitments in futures taken out as insurance on a particular contract could be liquidated upon execution (physical delivery between buyers and sellers) of said contract.

As in the initial proposal, and in addition to the governance issues, the key questions are: how large would these margins have to be, and who would invest in them? Will it require international support? If so, how will this be coordinated, especially during times of tight global supply? In addition, it poses two more 
key problems: first, the need to have a global storage mechanism in place and its necessary international governance; second, the need to specify any triggering mechanism that will make it effective, i.e., when the grain guarantee would be executed.

Finally, in the case of Wright (2009) and Lin's (2008) proposal, the most difficult part would clearly be persuading countries to commit to the IGCA and then adhere to it during a food crisis. When facing the choice between breaking international agreements and protecting their citizens by ensuring national food security, some countries are likely to impose export bans, regardless of any punitive actions against protective trade policies. Moreover, as shown by Martin and Anderson (2010), and Bouet and Laborde (2009), if export taxes are raised in a large agriculturalbased economy, world food prices will rise (through a reduction in world supply), which will hurt small net food-importing countries. The reduction of import duties has exactly the same effect: an increase in world prices through an expansion of demand in world markets. Furthermore, when export taxes are augmented in large food-exporting countries and import duties are reduced in large food-importing countries, small food-importing countries would be affected economically; thus, the solution is not only a facilitation of trade but also the understanding of the effects of different trade policies could have and to understand the importance of the required governance to prevent large countries from implementing policies aimed at maintaining constant domestic food prices. The costs of insufficient cooperation in and regulation of (binding process) such policies in a time of crisis is an extremely complex issue, and it is unclear whether the WTO dispute resolution mechanisms could be used effectively (see also Chap. 8 of this book by Bouët and Laborde).

\subsubsection{Reserves and Stocks}

There have been several proposals regarding physical reserves: (1) emergency reserves (ERs) (von Braun and Torero 2008); (2) international coordinated grain reserves (ICGRs) (Lin 2008; von Braun et al. 2009) and rice reserves (Timmer 2010); (3) regional reserves (RRs) by regional associations of governments; and (4) country-level reserves (CRs) by multilateral institutions, such as the World Bank.

The ERs is a modest emergency reserve of around 300,000-500,000 metric tons of basic grains-about $5 \%$ of the current food aid flows of 6.7 million wheatequivalent metric tons-which would be supplied by the main grain-producing countries and funded by a group of countries participating in the scheme. These countries would include the Group of Eight Plus Five $(\mathrm{G} 8+5)$ countries (Canada, France, Germany, Italy, Japan, Russia, the UK, the US, Brazil, China, India, Mexico, and South Africa) and perhaps other countries. This decentralized reserve would be located at strategic points near or in major developing country regions and make use of existing national storage facilities. The reserve, which would be used exclusively for emergency response and humanitarian assistance, would be managed by the World Food Programme (WFP). The WFP would have access to the grains at precrisis market prices to reduce the need for short-term ad hoc fundraising. To 
cover the cost of restoring the reserve to its initial level (i.e., the difference between the post and precrisis price multiplied by the quantity of reserves used by WFP), an emergency fund should be created, and its level maintained by the participating countries. The fund should be accompanied by a financing facility that the WFP could draw from as needed to cope with any potential increase in transport costs, as experienced in the 2008 crisis. This arrangement could also be defined under a newly designed Food Aid Convention. It should be solely for humanitarian purposes rather than the reduction of excessive price volatility. Following this initiative, the G20 has proposed studying the feasibility of a global humanitarian emergency reserve through a pilot implementation in West Africa under the leadership of ECOWAS and the support of the WFP.

The other three mechanisms had been proposed as ways to mitigate excessive price volatility. A combination of the proposed reserve systems would likely be necessary, but country-level reserves should be thought of as a strategic reserve rather than food stock held by marketing board/parastatals. Enforcing floor and ceiling prices by marketing boards or parastatals has always involved holding physical stocks of grains; there is significant evidence that these measures would distort markets (Rashid and Lemma 2010). Strategic grain reserves are different from such stocks. Strategic reserves were introduced in many countries because marketing boards failed to address shocks, such as the prolonged droughts in the countries of the Sahel region; however, they cannot be thought of as mechanisms to reduce international price volatility. Moreover, three key challenges arise when maintaining these types of strategic reserves: the determination of optimum stock levels, the level of costs and losses associated with these reserves, and the uncertainties that strategic reserves could cause in the market place. Not only is the process of determining optimum stock levels politically challenging, but reserves are also highly dependent on transparent and accountable governance. In addition, predicting supply, demand, and potential market shortfalls can be extremely difficult. Physical reserves also require financial resources and must be rotated regularly; in African countries, the costs of holding a metric ton of food ranged from US\$20 to US\$46 (Rashid and Lemma 2010). The countries that need reserves most are generally those which are least able to afford the costs and oversight necessary for maintaining them. The private sector is better financed and better informed and has more political power, which puts it in a much better position to compete than most of the governments that would be managing these reserves. Finally, the uncertainties that strategic reserves can introduce into the marketplace can be problematic.

With respect to the coordination of global reserves and regional reserves, in addition to high storage costs (both opportunity and effective costs when creating a new physical reserve) and the fact that the creation of reserves will put more upward pressure on prices during times of tight supply, there are several other concerns that need to be taken into account. First, similar to the security provisions of the IEA, the key challenge would be to develop a governance structure such that member countries would honor their commitments to the reserves even when markets are under stress. Second, the global or regional reserves would clearly require trigger mechanisms to determine when to release stocks to calm markets in times of stress. 
Such mechanisms are a necessary condition for a reserve to operate as a tool to reduce extreme price volatility. In addition, it is imperative to keep the trigger mechanisms highly transparent. The model proposed by Martins-Filho et al. (2010) could be a solution to address the need for transparency. Finally, a physical reserve, whether regional or global, would not resolve the problem of interlinkages within the financial, energy, and food commodity markets; the problem could be extremely relevant if excessive speculation is indeed a cause of extreme price spikes.

\subsubsection{Financial Instruments}

There are two major proposals linked to the use of financial instruments: (1) the virtual reserves proposed by von Braun and Torero (2008, 2009a, b) and (2) a toolbox of market-based risk management tools, such as physical or financial commodity price hedges, insurance and guarantee instruments, and counter-cyclical lending, which can play an important role in helping vulnerable countries mitigate and manage the risks associated with excessive food price volatility. The toolbox was proposed in the Paris G-20 meeting and is still in its planning stage.

The proposal of virtual reserves is a safeguard mechanism to manage risk through the implementation of a virtual reserve which is backed by a financial fund and is aimed at calming markets during extreme price volatility. The concept has been widely used by central banks for inflation targeting and dirty flotation of the exchange rates.

The virtual reserve concept incorporates a global market analysis unit (GMAU), which has two functions. First, and perhaps most importantly, the GMAU is an early warning mechanism based on a model [see Martins-Filho et al. (2010) for details about the model] that forecasts changes in returns for key staple commodities in the futures market and identifies when a price abnormality occurs or when a price spike appears imminent. When this price abnormality happens, it means that the realized return is an extreme value and there is a high probability that it will fall under the 95th percentile return on the following day or days; on the other hand, if the realized return remains over the 95th percentile, it could imply the formation of a price spike. The announcement of a potential price spike alerts the market to a higher likelihood of an intervention in the futures market, which will immediately increase the discount rate of potential short-term investors. If there is evidence of an emerging price spike despite this alert, the GMAU will indicate that returns are significantly above their normal. Finally, an autonomous technical committee would then decide whether to enter the futures market. This intervention would consist of executing a number of progressive short sales (that is, selling a firm promise-a futures contract - to deliver the commodity at a later date at a specified price) over a specific time period in futures markets at a variety of market prices in different futures months until futures prices and spot prices decline to levels within the estimated price bands. The GMAU would recommend the price or series of prices to be offered in the short sales. 
This increase in the supply of short sales will reduce spot prices and should help to significantly reduce extreme price volatility by reducing the probability of abnormal returns. In other words, the intervention will create a backwardation in the market (the situation in which, and the amount by which, the price of a commodity for future delivery is lower than the spot price or a far-month future delivery price is lower than a nearby month future delivery price). Reducing these abnormal returns would minimize potential second-round effects (such as export bans, export restrictions, or reduction of import tariffs), given that spot prices would again become consistent with market fundamentals; therefore, lower spot prices would not result in the accelerated use of available supplies. All futures contracts will ultimately be settled either through liquidation by offsetting purchases or sales (the vast majority of agricultural futures contracts are settled this way) or through delivery of the actual physical commodity. In this respect, the virtual fund will only stand for delivery if there is a need to realize the futures sales, in which case the fund will be used to obtain the necessary grain supply to comply with futures contract delivery requirements and calm the markets. Usually, this action would not be necessary and the whole operation would remain virtual because the signal will deter speculators from entering. Questions would remain about the price, the amount of short sales, and the duration of the intervention in the futures markets; answering these questions would require political consultation and continuous market monitoring and research.

The innovative concept behind the virtual reserve is the early warning alert system provided to markets and regulators. The presence of the system alone is likely to deter short-term financial investors from entering this market; the probability of a real intervention is minimal. Nonetheless, the committee must be ready to trade grain when necessary and to assume the potential costs of buying back contracts at a higher price than they were sold for. In that sense, a clear financial commitment is needed to give the correct signal to the market. The size of the initial commitment is still being studied. A comprehensive cost-benefit assessment of the system must look beyond agricultural markets and also include food security and poverty considerations.

The key advantages of the virtual reserve compared to a physical reserve are that (1) it involves a signaling mechanism, (2) it does not put more stress on commodity markets, (3) it does not incur the significant storage and opportunity costs of a physical reserve, (4) it resolves the problem of the interlinkages between the financial and the commodity markets, and (5) its effect on markets would be minimal because it is only a signal.

There are some critics of the virtual reserve concept. First, some have questioned whether rising futures prices actually lead to increased spot market prices; however, several studies suggested that changes in the futures prices of certain commodities generally lead to changes in spot prices. ${ }^{6}$ In addition, the recent analysis by Hernandez and Torero (2010) complements these earlier studies by examining causal

${ }^{6}$ See Garbade and Silber (1983); Brorsen et al. (1984); Crain and Lee (1996). 
relations in the current decade with a much more developed futures commodity market. Their analysis used both linear and nonparametric Granger causality tests and identified a causal link in all cases. The results indicated that spot prices are generally discovered in futures markets. In particular, they found that changes in futures prices in the markets analyzed led to changes in spot prices more often than the reverse case. Thus, from a policy perspective, these findings support the viability of implementing a global virtual reserve to address grain price abnormalities through signals in the futures market and, if necessary, market assessment in the exchange of futures.

Wright (2009) also argued that it would be difficult for the responsible parties to be certain that markets are out of equilibrium and that the proposed interventions would not do more harm than good under any given circumstances. In this sense, the model developed by Martins-Filho et al. (2010) has made significant progress toward the capacity to predict price abnormalities, as previously explained. There has also been significant concern regarding the size of the financial funds necessary to ensure the success of the signal given by the virtual reserve. In that respect, the virtual reserve requires a coordinated commitment from the group of participating countries. Each country needs to commit to supplying funds, if needed, for intervention in grain markets; this does not imply effective expenditure. Therefore, the resources needed are promissory rather than actual budget expenditures. Further analyses are required to determine the size of this fund because commodity futures markets allow for high levels of leverage. This commitment cannot be compared with budgets allocated for R\&D. First, it is a commitment rather than an expenditure; second, the size of this commitment should be significant enough to provide a strong signal to the market. It is noteworthy that similar activities have been implemented by central banks, such as the dirty flotation of the US dollar, a practice whereby the US central bank uses reserves to maintain the target limits of appreciation or depreciation of the currency within a certain range. Finally, there is also a question of the governance behind the virtual reserve mechanism. Clearly, reaching an agreement on the arrangements of the virtual reserve would not be easy and may require a high-level United Nations task force to analyze the way forward. Yet similar institutional arrangements have been made in the past; examples include the International Fund for Agricultural Development (IFAD), the Food Aid Convention (FAC), the IMF Cereal Import Facility, and the IEA. The IFAD was established as an international financial institution in 1977 and was a major outcome of the 1974 World Food Conference in response to the food crisis of the early 1970s. The FAC, which was first signed in 1967 and have since been renewed five times, is the only treaty under which the signatories have a legal obligation to provide international development assistance.

With respect to the toolbox of risk-coping mechanisms, there are basically two initiatives being implemented. First, the International Finance Corporation (IFC)'s new Agriculture Price Risk Management (APRM) product will allow producers and consumers to hedge against downside or upside price risk on a pilot basis by using a financial intermediary with both global reach and expertise in Latin America. Efforts to introduce the APRM product will be supported by two other financial 
intermediaries focusing on lower income countries in sub-Saharan Africa, North Africa, and the Middle East. In addition, other multilateral and regional development banks are exploring their interest in risk-sharing by using APRM facilities in order to take advantage of APRM's operational infrastructure. Nevertheless, as the literature has pointed out, the pickup rate of these insurance tools and their cost effectiveness still needs to be assessed. Second, the World Bank has developed a proposal to facilitate governments' access to risk management markets by providing assistance in structuring and executing financial and physical commodity risk hedging, and in building the legal/regulatory/technical capacity required for using these tools. The impact and process of this mechanism need to be evaluated to ensure its effectiveness, viability, and sustainability.

\subsubsection{Regulatory Proposals}

Since late 2005, a number of serious problems have plagued the futures and cash markets for grains (corn, soybeans, and wheat). The most dominant problem is lack of price convergence between cash and futures prices (see, for example, Garcia et al. 2014 and Adjemian et al. 2013). There seem to be several factors related to the uncoupling of cash and futures prices. The first concerns delivery certificates, which are issued by warehouses to those holding a long position in the futures market until the contract expires. The problem in this case is that the parties holding long positions are not using these certificates to take delivery but are holding them, in part because of the value the certificates retain. The second problem is that actual delivery is not occurring. Many market participants believe that the lack of load-out is contributing to the lack of convergence in futures and cash prices. Because the demand for delivery is diminished, storage facilities have less space available. This raises a concern about storage rates, which should be reviewed to ensure that they are kept at the right levels. An incorrect storage rate could contribute to the uncoupling of cash and futures prices. Proposed solutions for the lack of price convergence include changing the storage facility fees, changing the futures contract to a cashsettled contract, changing the design of the delivery instrument, compelling load-out (i.e., compelling entities with long positions to stand for delivery), and reviewing trading patterns of fund traders to ascertain their effect on the market.

The Commodity Futures Trading Commission (CFTC) and other agencies of the US government and the European Commission, along with the futures industry, have reviewed proposals and implemented seasonal storage rates, limits on the number of delivery certificates an entity can hold for noncommercial purposes, and an additional issue of the Commitment of Traders report to increase transparency. If these structural changes do not significantly improve the price convergence between futures and cash prices, then a cash-settled contract must be seriously considered. In any regard, exchanges and regulators cannot afford to continue pursuing solutions at a slow pace. These problems began in late 2005, and so far very few structural changes have occurred. 
Despite these regulatory measures being seemingly complementary to many of the proposals described above, a major problem hindering any regulatory mechanism in futures exchanges is the level of linkages between the main futures commodity markets. If activities in different future exchanges mutually influence each other, then regulations implemented in an exchange would merely transfer the problem to another exchange; this again requires managing the complexity of multicountry coordination, as in the case of the virtual reserve or any global or regional reserves.

Possible solutions to address potential excessive speculation include imposing stricter speculative limits and larger margins, phasing out existing position limit waivers for index traders, imposing additional restrictions on index traders, investigating index trading in other agricultural markets, and strengthening data collection on index trading in nonagricultural markets.

To summarize the analysis of all proposed alternatives, Fig. 6.3 classifies the major proposed initiatives based on their cost (horizontal axis) and their effectiveness in reducing price volatility (vertical axis). It is important to mention that only these two dimensions are used because the major objective of this chapter is to identify the existing mechanisms proposed and their effectiveness in reducing price volatility. In that respect, some of these initiatives, such as the emergency food reserves (von Braun and Torero 2009a, b) and the food import facility (Sarris 2009), have objectives other than reducing price volatility; therefore they were ranked low in that dimension. This does not mean that they are ineffective in meeting their core objective. On the other hand, policies such as the virtual reserves (von Braun and Torero 2009a, b), the internationally coordinated grain reserves (Lin 2008), the regional reserves (such as the ASAEN), and the International Grain Clearance Agreement (Sarris 2009) were ranked higher in terms of effectiveness in reducing price volatility, although they vary significantly in the amount of resources needed for their implementation and in the amount of additional research required to implement them properly.

\subsection{Conclusion}

The international food price crises of 2007-2008 and 2010 led to economic difficulties for the poor, generated political turmoil in many countries, and could have severely affected confidence in global grain markets, thereby hampering the market's performance in responding to fundamental changes in supply, demand, and the costs of production. More importantly, food crises could result in unreasonable or unwanted price fluctuations, which could harm the poor and cause long-term, irreversible damage to the body because of malnutrition, especially among children. The food crises highlighted the need to modify the architecture of international financial and agricultural markets in order to address the problem of price spikes.

Appropriate global institutional arrangements for preventing such market failures are missing. A global solution to prevent excessive price volatility in food markets may be costly, but given the losses caused by food price crises like those in 


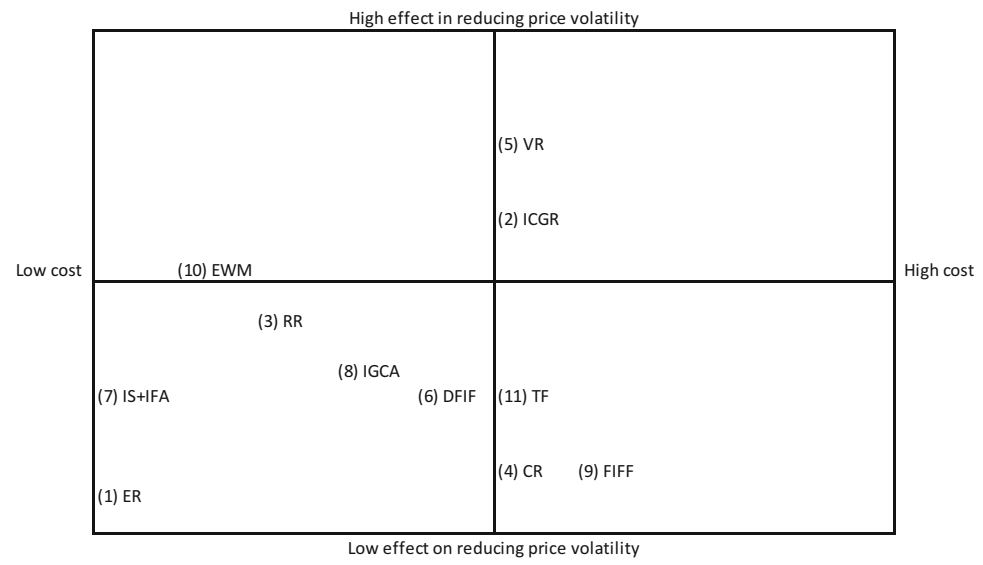

Fig. 6.3 Proposals for reducing price volatility. Note: The vertical axis refers to the potential effect in reducing price volatility and the horizontal axis to the costs required for its implementation. (1) $\mathrm{ER}=$ emergency reserve, von Braun and Torero (2009a, b), it requires US\$7.5 Mpa but is to alleviate requirements of WFP during food scarcity and not to reduce price volatility. (2) ICGR = internationally coordinated grain reserves, Lin (2008), it implies opportunity costs and coordination costs (approx. US\$1.05 Bpa) and it could have an impact in reducing volatility but high risks of coordination failure, requires capacity to predict price spikes, and not necessarily effective to tackle speculation in futures market. Timmer (2010) proposes a similar idea only for rice given how concentrated this market is we expect it to have a higher effect in reducing volatility in this specific commodity. (3) RR = regional reserves as the one of ASEAN, it implies opportunity costs and coordination costs; depending on the market share on the commodities of the countries involved, it could have an impact in reducing volatility, but very high risks of coordination failure, and could distort market prices, patronage problems, and other principal agent problems. (4) $\mathrm{CR}=$ country level reserves, this could imply significant relative costs at the country level, significant distortions, and little effect on volatility given low effect over international markets. (5) VR = virtual reserves, von Braun and Torero (2009a, b), it requires US\$12-20 B, risk of coordination failure, requires capacity to predict price spikes, could be effective in tackling speculation in futures market, requires certainty that markets are out of equilibrium to avoid distortion of interventions. (6) DFIF = diversion from industrial and animal feed uses, Wright (2009), it implies opportunity costs, could distort market efficiency, and necessarily effective to tackle speculation in futures markets. (7) IS + IFA = better Information on Storage and International Food Agency (Wright 2009), very low cost not clear effectiveness in reducing price volatility (8) IGCA = International Grain Clearance Arrangement, Sarris (2009). Not too costly, not clear how it will operate, not clear size of margins, not clear if it will work when stocks are tight, and not necessarily effective to tackle speculation in futures markets. (9) FIFF $=$ food import financing facility, Sarris (2009). Similar to IMF's food import facility, could be costly, possible moral hazard problems, and not effective to tackle speculation in futures markets. (10) $\mathrm{EWM}=$ early warning mechanism. (11) TF $=$ trade facilitation-Wright (2009) and Lin (2008)

2007-2008 and 2010, such solution would still have large positive net returns. Clearly, some of the key drivers behind the excessive price volatility can be directly addressed by, for example, revising biofuel policies through curtailing biofuel subsidies, making mandates flexible and liberalizing biofuel and feedstock trade. Another way to address the problem is by increasing and diversify global 
productivity and production in order to raise the number of countries that export staple foods and, at the same time, increase aggregate global reserves to the minimum critical level needed.

On the other hand, the incentives for excessive financial activity in the food commodity futures markets, which is one of the causes of price volatility, could be reduced by (1) changing regulatory frameworks to limit the volume of speculation versus hedging, (2) making delivery on contracts or portions of contracts compulsory, and (3) imposing capital deposit requirements on every futures transaction. These regulatory measures could be implemented on a case-by-case basis or as a platform through an international "alliance of commodity exchanges." Therefore, there is a need to discuss exchange regulation and the role of speculative traders, and this discussion must include the issue of international harmonization of any regulatory policy to increase the probability of successful policy implementation. There is also a clear need to improve the quality of information on and forecasting of price spikes for any of these potential policies to work properly. AMIS could be an important option for addressing this issue.

Several of the proposals that are specifically for reducing price volatility or the effects of the price crises require significant and quick investment in further research into their implementation and potential risks and benefits. In addition, many of them have different objectives and therefore could substantially complement each other. For example, the following three proposals complement each other: (1) von Braun and Torero's (2009a) proposal of emergency humanitarian reserves and a financial instrument to reduce the incentives for excessive speculation, (2) Lin's (2008) proposal of an international coordinated regional reserve, ${ }^{7}$ and (3) Wright's (2009) proposal of providing better information regarding storage and the development of an international food agency. Moreover, the institutional design of the virtual reserve concept included a specialized research unit that would not only improve information regarding storage but also enhance the capacity of monitoring the probability distribution of price spikes and the periods of excessive volatility (similarly to what is being implemented through AMIS). While the proposed actions will entail costs, the modest costs of the required organizational elements must be balanced against the benefits of more effective international financial architecture. The benefits include the prevention of economic hardship and political instability, improved market efficiency, and stronger incentives for long-term investment in agriculture.

All other proposals focused on different objectives and do not seem to have the potential to significantly reduce price volatility; nevertheless, they may have positive effects on other issues, such as trade financing (Sarris 2009) and the longterm effects of some of the variables behind the changes in supply and demand fundamentals (Wright 2009).

In the meantime, we observed a diverse set of policy actions being taken: many countries try to build up costly national reserves, others focus on increasing self-

\footnotetext{
${ }^{7}$ See von Braun et al. (2009) for a joint proposal.
} 
sufficiency, and still others engage in FDI to secure national food security through transnational land acquisition rather than trade because of lost confidence in trade owing to uncertainty surrounding volatility. In addition, some countries are pressing for more regulation of exchanges, which would not prevent extreme price spikes and could even further distort markets. All of these policy actions threaten to move food agriculture further away from efficient market designs. A more promising step may be regional coordinated reserves, as recently planned by ASEAN. Nevertheless, a global problem needs global institutional responses.

A clear message from all these proposals is that comprehensive research is needed to provide the decision-making body with independent and trustworthy information on possible alternatives for coping with the new global scenario of price spikes and excessive price volatility. All of these alternatives would clearly benefit from improved information availability. At the same time, improving information availability would allow for better evaluation of the costs and benefits of each proposal.

Open Access This chapter is distributed under the terms of the Creative Commons AttributionNoncommercial 2.5 License (http://creativecommons.org/licenses/by-nc/2.5/) which permits any noncommercial use, distribution, and reproduction in any medium, provided the original author(s) and source are credited.

The images or other third party material in this chapter are included in the work's Creative Commons license, unless indicated otherwise in the credit line; if such material is not included in the work's Creative Commons license and the respective action is not permitted by statutory regulation, users will need to obtain permission from the license holder to duplicate, adapt or reproduce the material.

\section{References}

Adams R Jr (1983) The role of research in policy development: the creation of the IMF Cereal import facility. World Dev 11(7):549-563

Adjemian MK, Garcia P, Irwin S, Smith A (2013) Non-convergence in domestic commodity futures markets: causes, consequences, and remedies (no. 155381). United States Department of Agriculture, Economic Research Service

Bakary S (2008) The new face of hunger. The Economist, 17 April

Bouet A, Laborde DD (2009) The potential cost of a failed Doha round. In: 12th annual conference on global economic analysis, Santiago, Chile

Brahmbhatt M, Christiaensen L (2008) Rising food prices in East Asia: challenges and policy options. World Bank, Washington, DC. Available at http://siteresources.worldbank.org/ EASTASIAPACIFICEXT/Resources/EA_Rising_Food_Prices050508.pdf

Brorsen BW, Bailey D, Richardson JW (1984) Investigation of price discovery and efficiency for cash and futures cotton prices. West J Agric Econ 9(1):170-176

Calvo G (2008) Exploding commodity prices, lax monetary policy, and sovereign wealth funds. VoxEU, 20 June

Crain S, Lee JH (1996) Volatility in wheat spot and futures markets, 1950-1993: government farm programs, seasonality, and causality. J Finance 51(1):325-343

De Schutter O (2010) Food commodity speculation and food price crises, regulation to reduce the risks of price volatility

Evans A (2009) The feeding of the nine billion: global food security for the 21st century. Chatham House, London 
FAO (1980) The state of food and agriculture 1980. Food and Agriculture Organization, Rome

Food and Fuel Prices-Recent Developments, Macroeconomic Impact, and Policy Responses Prepared by the Fiscal Affairs, Policy Development and Review, and Research Departments (In consultation with other departments) Approved by Teresa Ter-Minassian, Mark Allen, and Simon Johnson, available at: https://www.imf.org/external/np/pp/eng/2008/063008.pdf

Galtier F (2009) How to manage food price instability in developing countries. Working paper, no. 5. Moisa

Garbade K, Silber W (1983) Price movements and price discovery in futures and cash markets. Rev Econ Stat 65(2):289-297

Garcia P, Irwin SH, Smith A (2014) Futures market failure? Am J Agric Econ 97(1):40

Gilbert CL (1987) International commodity agreements: design and performance. World Dev 15(5):591-616

Gilbert CL (1996) International commodity agreements: an obituary notice. World Dev 24(1):1-19

Gilbert C (2010) How to understand high food prices. J Agric Econ (April 2010):1-28. Preliminary online version

Headey D, Fan S (2010) Reflections on the global food crisis. How did it happen? How has it hurt? And how can we prevent the next one, Research monograph 165. IFPRI, Washington, DC

Hernandez M, Torero M (2010) Examining the dynamic relationship between spot and futures prices of agricultural commodities. Commodity Market Review 2009-2010, pp 47-87

HM Government (2010) The 2007/08 agricultural price spikes: causes and policy implications. Department for Environment Food and Rural Affairs, London. Available at http://www.defra. gov.uk/foodfarm/food/pdf/ag-price100105.pdf

Huddleston B, Johnson GD, Reutlinger S, Valdés A (1984) International finance for food security. The Johns Hopkins University Press, Baltimore, MD

Irwin SH, Sanders DR, Merrin RP (2009a) Devil or angel? The role of speculation in the recent commodity price boom (and bust). J Agric Appl Econ 41:393-402

Irwin SH, Garcia P, Good DL, Kunda EL (2009b) Poor convergence performance of CBOT corn, soybean and wheat futures contracts: causes and solutions. Marketing and outlook research report 2009-02, Department of Agricultural and Consumer Economics, University of Illinois at Urbana-Champaign, March 2009

Irwin S, Good D, Garcia P, Kunda E (2009c) Comments on Permanent Senate Subcommittee on Investigations report 'excessive speculation in the wheat market'. Department of Agricultural and Consumer Economics, University of Illinois. July 2009. Available under 'Miscellaneous Publications' at http://www.farmdoc.uiuc.edu/irwin/research.html

Lin J (2008) Prepared remarks presented at the roundtable on 'preparing for the next global food price crisis', Center for Global Development, Washington, DC, 17 October 2008

Lipsky J (2008) Commodity prices and global inflation, remarks at the Council on Foreign Relations, New York City, 8 May 2008

Martin W, Anderson K (2010) Trade distortions and food price surges. Paper for the World BankUC Berkeley conference on agriculture for development-revisited, Berkeley, 1-2 Oct 2010

Martins-Filho C, Torero M, Yao F (2010) Estimation of quantiles based on nonlinear models of commodity price dynamics and extreme value theory. IFPRI, Mimeo. Available at http://www. foodsecurityportal.org/policy-analysis-tools/wheat-prices-and-returns

OECD (2008) Rising food prices: causes and consequences (OECD policy report). Organisation for Economic Co-operation and Development, Paris. Available at http://www.oecd.org/dataoecd/ 54/42/40847088.pdf

Rashid S, Lemma S (2010) Strategic grain reserve in Ethiopia: institutional design and operational performance. IFPR discussion paper 01054, January 2011, Washington, DC

Robles M, Cooke B (2009) Recent food prices movements: a time series analysis. Discussion paper 942. International Food Policy Research Institute, Washington, DC

Robles M, Torero M, von Braun J (2009) When speculation matters (Issue brief 57). International Food Policy Research Institute, Washington, DC. Available at http://www.ifpri.org/pubs/ib/ ib57.asp

Rojas-Suarez L (2008) The right response in Latin America to oil and food price pressures: fight inflation now! Center for Global Development, Washington, DC 
Rosegrant MW, Zhu T, Msangi S, Sulser T (2008) The impact of biofuel production on world cereal prices. International Food Policy Research Institute, Washington, DC. Unpublished paper, quoted with permission, July 2008

Sanders DR, Irwin SH (2010) A speculative bubble in commodity futures prices? Cross-sectional evidence. Agric Econ 41:25-32

Sarris A (2009) Hedging cereal import price risks and institutions to assure import supplies. FAO working paper

Shaw DJ (2007) World food security: a history since 1945. Palgrave Macmillan, New York

Sommer M, Gilbert C (2006) The boom in nonfuel commodity prices: can it last? World Econ Outlook 35:1-31, Chapter 5

Timmer CP (2010) Reflections on food crises past. Food Policy 35:1-11

UNCTAD (2009) World investment report 2009. Transnational corporations, agricultural production and development, United Nations

Valdés A (ed) (1981) Food security for developing countries. A Westview special study. Westview, Boulder, CO

von Braun J (2008a) Food summit: some progress but more needs to be done (Press statement release, 6 June 2008). International Food Policy Research Institute, Washington, DC. Available at http://www.ifpri.org/pressrel/2008/20080606.asp

von Braun J (2008b) Biofuels, international food prices, and the poor (Testimony to the United States Senate Committee on Energy and Natural Resources, 12 June 2008). International Food Policy Research Institute, Washington, DC. Available at http://www.ifpri.org/pubs/testimony/ vonbraun20080612.asp\#dl

von Braun J (2008c) Rising food prices: what should be done? (Policy brief, April 2008). International Food Policy Research Institute, Washington, DC. Available at http://www.ifpri. org/pubs/bp/bp001.asp

von Braun J, Torero M (2008) Physical and virtual global food reserves to protect the poor and prevent market failure. Policy brief 4, June 2008. International Food Policy Research Institute, Washington, DC. Available at http://www.ifpri.org/pubs/bp/bp004.pdf

von Braun J, Torero M (2009a) Implementing the physical and virtual food reserves to protect the poor and prevent market failure. Policy brief 10, February 2009. International Food Policy Research Institute, Washington, DC. Available at http://www.ifpri.org/pubs/bp/bp010.pdf

von Braun J, Torero M (2009b) Exploring the price spike. Choices 24(1). Available at http://www. choicesmagazine.org/magazine/article.php? article $=58$

von Braun J, Ahmed A, Okyere KA, Fan S, Gulati A, Hoddinott J et al (2008) High food prices: the what, who, and how of proposed policy actions. Policy brief, May 2008. International Food Policy Research Institute, Washington, DC. Available at http://www.ifpri.org/PUBS/ib/ FoodPricesPolicyAction.pdf

von Braun J, Lin J, Torero M (2009) Eliminating drastic food price spikes-a three pronged approach for reserves. Note for discussion

Wiggins S, Keats S (2009a) Volatile world food prices and their implications: grain stocks and price spikes. Overseas Development Institute, London

Wiggins S, Keats S (2009b) Annex 2, Grain stocks and price spikes. Overseas Development Institute, London

World Agricultural Outlook Board (2008) World agricultural supply and demand estimates. WASDE-460, USDA, Washington, DC

Wright B (2008) Speculators, storage, and the price of rice. Giannini Foundation of Agricultural Economics, University of California, Berkeley, CA

Wright B (2009) International grain reserves and other instruments to address volatility in grain markets. The World Bank. Policy Research Working Paper 5028. August

Wright BD, Bobenrieth E (2009) The food price crisis of 2007/2008: evidence and implications. Food outlook: global market analysis. FAO, Rome 